\title{
EXPANSÃO E OLIGOPOLIZAÇÃO DA EDUCAÇÃO SUPERIOR NO BRASIL
}

\begin{abstract}
Waldemar Marques*
* Doutor em Educação pela Universidade Estadual de Campinas. Professor do Programa de Pós-graduação em Educação - UNISO. Sorocaba, SP, Brasil. E-mail: waldemar.marques@prof.uniso.br

Resumo: Este texto analisa a expansão da educação superior no Brasil num período que cobre mais de meio século, com destaque para os governos que se seguem ao golpe militar de 1964 até os dias atuais. Aborda o crescimento constante do setor privado da educação superior no país destacando seu processo de concentração em grandes grupos educacionais, configurando-se como oligopólios que extrapolam fronteiras nacionais e ampliam seu poder mediante operações na bolsa de valores. Aborda também o papel do Estado brasileiro e sua atuação dúbia a permitir ou facilitar o crescimento desordenado do setor privado nesta área de vital importância para a nação.
\end{abstract}

Palavras chave: Educação superior. Oligopolização. Expansão.

\section{EXPANSION AND OLIGOPOLIZATION OF HIGHER EDUCATION IN BRAZIL}

Abstract: This text analyzes the expansion of higher education in Brazil during a period that covers more than a half century, with emphasis on governments that follow the 1964 military coup until nowadays. It discusses the constant development of the private sector of higher education in the country, emphasizing its concentration process in large educational groups, configuring itself as oligopolies extrapolating national borders and expanding power by stock market operations. It furthermore discusses the role of the Brazilian State and its dubious performance to allow or facilitate the disordered development of the private sector in this field of vital importance to the nation.

Keywords: Higher education. Oligopolization. Expansion.

\section{A EDUCAÇÃO PÚBLICA SUPERIOR SE AFIRMA}

No período que vai de 1945 a 1964, a sociedade brasileira viveu um tempo de liberdades democráticas quando intelectuais, professores e estudantes vinculados à União Nacional de Estudantes (UNE) e Sociedade Brasileira para o Progresso da Ciência (SBPC) atuavam fortemente em direção à democratização da educação, gestando neste período propostas inovadoras para a educação superior. Este período apresenta um grande crescimento da educação superior pública no país, passando a matrícula de 21 mil para 182 mil, uma taxa de $1.154 \%$ (MARTINS, 2009, p. 2), indicativa do processo da democratização que tomava conta do país. Não só a taxa de crescimento da educação superior é indicativo de sua afirmação, como também esta expansão resulta da atuação direta do poder público. Ao final deste período, 61.3\% (CUNHA, 2007, p. 79) das matrículas se concentravam em instituições públicas; o que era até então conhecida como educação superior particular estava vinculada predominante- 
mente a instituições religiosas, sem o caráter empresarial, mercadológico difundido hoje no Brasil. Foi um período de grande efervescência política e prenhe de grandes possibilidades interrompido em sua trajetória pelo golpe militar de 1964.

\section{A VIRADA NA EDUCAÇÃO SUPERIOR}

O fim dos anos 60 marca os primeiros momentos de um processo de mudança radical na educação superior no Brasil que se expressa nos números e na organização desse nível educacional. A Reforma da Educação Superior de 1968 (Lei ${ }^{\circ} 5.540$ ) implementada pelo governo militar dá início a grandes alterações na organização deste nível de ensino: promove a expansão das universidades públicas enquanto parte do projeto de desenvolvimento econômico do país no governo militar, abre as portas para a proliferação das instituições privadas de educação superior e ao mesmo tempo amplia a perseguição aos opositores do novo regime e sua eliminação dos quadros docentes das universidades públicas. A universidade deixa de ser a referência privilegiada de organização deste nível de ensino, multiplicando-se, a partir dos anos 70, instituições isoladas de educação superior, impulsionadas por forte demanda, pela alegada escassez de recursos financeiros na esfera pública e pela possibilidade de grandes lucros a atrair a atenção da iniciativa privada. Não menos importante neste processo que inaugura o novo panorama da educação superior, é a leniência do poder público em controlar o surgimento de instituições privadas de educação superior, que se manifesta na fácil aprovação para funcionamento destas instituições (MARTINS, 2009, p. 4).

O fato é que a partir de então, no evoluir da educação superior, a presença das instituições de ensino superior (IES) privadas, movidas pela oportunidade do lucro, progressivamente passam a dominar o cenário de educação superior brasileira. A ausência dos protagonistas do cenário político anterior, silenciados ou simplesmente eliminados, deixa livre o caminho para os que propunham maior presença da iniciativa privada na educação superior, quer por uma visão falsamente liberal de sociedade, quer por motivos simplesmente de busca de lucro, motivos estes certamente nunca explicitados, ainda que os mais determinantes.

Hoje, decorridas mais que quatro décadas, a trajetória ascendente da iniciativa privada na educação superior no Brasil mantém o mesmo vigor. Neste longo evoluir, sua presença adquire diferentes contornos, metamorfoseia-se, mas prossegue em sua marcha. Num período de quinze anos, de 1965 a 1980, 
em pleno governo militar, as matrículas nas instituições privadas que no início deste período alcançavam 44\% do total de matrículas da educação superior, proporção já então bastante elevada,em 1980 chegam a 64\% (MARTINS, 2009, p. 4). Assim, no que se refere ao alcance da educação superior no país, em termos de matrícula, a educação superior pública perde significativamente sua hegemonia. A iniciativa privada passa a absorver, a partir de então, a maior parte das matrículas na educação superior, num caminho que, ao que parece até os dias de hoje, sem volta.

A desaceleração do crescimento da educação superior na década de 80 , reflexo da crise econômica que também passa a exaurir o governo militar, não chega a alterar basicamente o quadro de predominância alcançado pelo setor privado, mesmo com a pequena diminuição da matrícula neste setor e o também pequeno aumento no setor público (MARTINS, 2009, p. 5).

\section{A DIFERENÇA SE AMPLIA}

Encerrado o período de governo militar que teve a duração de um quarto de século, seria de se esperar, em decorrência de sua extinção, o revigoramento progressivo das pressões sociais e da mobilização das energias políticas em direção à retomada da presença do poder público na construção de uma educação superior mais ampliada no seu alcance social, preservada sua qualidade. Contudo, os dados apontam que isto não aconteceu; persistiram e se fortaleceram os mesmos caminhos abertos na vigência do governo militar: a expansão da educação superior privada. Desta feita, a atuação do poder público alimentada por uma visão neoliberal sobre o Estado e seu papel na sociedade, seguindo orientação, quando não pressão, de instituições internacionais, restringiu os recursos para a educação pública superior, fortalecendo ainda mais o setor privado, já então predominante. Entre 1995 e 2002, as matrículas no setor privado passam de $60 \%$ para $70 \%$ do total de matrículas na educação superior, tendo aumentado de 1,7 milhões para 3,5 milhões de estudantes neste período, a uma taxa de 209\% (MARTINS, 2009, p. 5).

\section{O ENIGMA DO PRESENTE}

O século XXI se inicia para o Brasil com uma mudança de governo respaldado, desta feita, por amplo apoio de base popular (sindicatos dos trabalhadores, movimentos sociais, intelectuais, estudantes, igreja) vencida a resistência das elites conservadoras, mais próximas do poder econômico e do controle ideológico. 
Na primeira década deste novo século, a matrícula na educação superior no Brasil mais que dobra: de 3.036.113 matriculados em 2001, alcança 6.379.299 em 2010 (BRASIL, 2011, p. 8).

A partir de 2002, começa-se a perceber notável mudança na política para a educação superior com forte investimento nas universidades públicas federais: criação de novas universidades, ampliação das existentes, criação de novos cursos, contratação de professores e criação de novos campi. Políticas de ações afirmativas buscam promover a inclusão de estudantes de camadas da população tradicionalmente fora da educação superior. Assim, enquanto as matrículas nas instituições de educação superior estaduais e municipais sofrem um recuo, sobretudo nos três últimos anos deste período, com as federais ocorre o contrário; nestas registra-se elevação da matrícula.

Esta constatação, contudo, não chega nem de perto a constituir ameaça à iniciativa privada. É o que demonstram os dados: entre 2001 e 2010 as matrículas nas instituições públicas aumentaram de 944.584 para 1.643 .298 , a uma taxa de $42.5 \%$. Já as matrículas nas instituições privadas aumentaram neste mesmo período de 2.091 .529 para 4.736 .001 em 2010, a uma taxa de $55.8 \%$, bastante superior à taxa de crescimento das instituições públicas. Esta diferença adquire significado mais forte devido ao fato de que as matrículas na educação superior privada correspondem a 3/4 do total das matrículas, diferença que vem-se mantendo constante desde 2006. Quantitativamente, portanto, a taxa de crescimento da matrícula aliada ao volume da matrícula na educação superior privada sinaliza forte aumento de poder e influência nos rumos da educação superior no país. Mesmo que a proporção das matrículas no setor privado em relação ao setor público tenha se mantido estável nos últimos quatro anos desta década, é inegável a persistência da hegemonia do setor privado. Em 2010, 74.2\% das matrículas estão no setor privado, e $25.8 \%$ estão no setor público. Para tristeza daqueles que apostavam num quadro mais otimista, verifica-se hoje que, para quatro estudantes matriculados na educação superior no Brasil, apenas um vai para uma instituição pública, os outros três para instituições privadas.

A permanência das proporções entre as matrículas no setor público e no setor privado da educação superior nestes últimos quatro anos desta década sugere um quadro de equilíbrio quando a educação superior privada chegou no seu limite de expansão, o que parece não assustar tanto quando se compara com o que ocorreu no governo anterior, ocupado em reduzir o tamanho do estado brasileiro, com políticas alimentadas por uma visão neoliberal do Estado e da economia.

Porém, um mergulho para além das estatísticas pode revelar um quadro ainda mais preocupante da educação superior no Brasil do que estas mesmas indicam. 
As décadas de 70 e 80, marcaram um período de multiplicação de instituições de educação superior isoladas, quebrando a hegemonia da universidade como modo de organização da educação superior. As décadas seguintes registraram um forte aumento de universidades particulares, num processo de concentração próprio do que ocorre na economia capitalista. Ao quadro atual da educação superior de diversidade institucional e hegemonia das particulares, acrescentase o processo de oligopolização da educação superior.

Dias Sobrinho (2005), estudioso da educação superior no Brasil no contexto globalizado já alertava para o fato da educação superior sem fronteiras e sua inserção na órbita do mercado. Na mesma linha de percepção crítica, Chaves (2010, p. 5) afirma que desde 2007 "observa-se um forte movimento de compra e venda de IES no setor privado", emergindo deste processo "gigantes da educação" com enorme poder, já que operam no mercado de capitais através da bolsa de valores. A autora destaca o caso da Anhanguera Educacional, "empresa líder em aquisições e fusões de IES”. Em 2008 (CHAVES, 2010, p. 5-6), o grupo educacional Anhanguera possuía 52 unidades de educação superior com 720.000 matriculados. Outro grupo educacional, Estácio Participações, possuía 23 unidades, com 207.079 matriculados. A Kroton Educacional, da rede mineira Pitágoras, possuía 25 IES no país. O Sistema COC de Educação e Comunicação, também proprietário de diversas IES, tinha neste ano 8.934 matriculados em cursos presenciais e 19.875 em cursos semi-presenciais. Juntas, apenas quatro empresas educacionais, absorvem perto de um quarto das matrículas no setor privado, e perto de um quinto do total das matrículas da educação superior no país.

Os números desta expansão/concentração são eloqüentes. A entrada do grupo Anhanguera na bolsa de valores resultou numa valorização de $70 \%$ de suas ações, num período de apenas 6 meses. Em menos de um ano, o patrimônio do grupo teve uma valorização de 45\%! Oliveira, $(2009$, p. 6) assinala que "de 2001 a 2008 o setor do ensino privado aumentou seu movimento de capitais de R\$ 10 bi para 90 ! Nenhum setor da economia brasileira cresceu tanto no período".

Esta tendência prossegue nos anos mais recentes. Artigo de Naiana Oscar publicado na revista Exame (2012) afirma que em 2011 ocorreram 27 operações de aquisição de grupos educacionais, envolvendo a soma de 2,4 bilhões de reais. A Universidade Bandeirante (UNIBAN) foi incorporada à Anhanguera por 510 milhões de reais. A Kroton, numa operação classificada pela articulista como "a maior venda da história", adquiriu a Universidade do Norte do Paraná (UNOPAR), uma "mina de ouro", pelo valor de 1,3 bilhão de reais. A educação superior privada no Brasil é tratada como outro negócio qualquer de 
mega-dimensões, onde segundo Osman em artigo publicado na ISTOÉ Dinheiro, empreendedores brasileiros de sucesso que lideraram o surgimento da "maior cervejaria do planeta" estão "apostando alto em outro ramo no Brasil, o de educação". Neste processo é forte a presença de bancos privados nacionais e grupos estrangeiros. Nas palavras de Osman (2008), "como diversos outros negócios, a escala é uma palavra de ordem no setor da educação. E o caminho mais curto para atingi-la é a aquisição de unidades menores de ensino". Assim, ao histórico poder de influência do setor privado na educação superior no Brasil, alia-se presentemente o poder declaradamente econômico/financeiro que a atuação de grandes grupos e a participação na bolsa de valores permitem. São, portanto, fortes indicações de um processo de oligopolização da educação superior em curso no Brasil, perseguindo neste setor de atividade a lógica do desenvolvimento capitalista mais amplo.

Há um agravante deste processo que cabe aqui mencionar. Associados ao processo de expansão/oligopolização estão os mecanismos de propaganda praticados pelas instituições particulares de educação superior visando criar imagem de competência e qualidade, que promova o aumento da procura, buscando criar posição vantajosa de mercado. Um fato leva a outro; são inseparáveis. O jornal O Estado de São Paulo publicou matéria assinada por Sergio Pompeu, Carlos Lordelo, Cedê Silva (2012) que implica a 4ª maior universidade do país (particular) acusada de selecionar os melhores alunos para realizar o Exame Nacional de Desempenho de Estudantes (ENADE), instrumento que avalia o desempenho dos estudantes no início e final do curso de graduação. Os artigos do jornal apontam que o desempenho dos estudantes teria sido elevado artificialmente mediante a exclusão daqueles alunos de baixo rendimento para participar das provas do ENADE apresentando para tanto dados de difícil refutação. Vinte dias depois, na mesma seção, este mesmo jornal em artigo assinado por Paulo Saldanha denuncia que outras trinta instituições particulares de educação superior estão envolvidas em fraude similar. Tal fato indica como as regras que presidem o "jogo" do mercado (competição, criação e venda de imagem institucional, marketing) passam a fazer parte do universo acadêmico quando a presença do público se enfraquece frente ao privado.

Para aqueles que propõem o Estado "enxuto", cuja atuação se limite a incentivar, no jogo do mercado, os agentes sociais e econômicos como propulsores do desenvolvimento, o quadro de predominância do setor privado na educação superior brasileira certamente parecerá positivo. Porém, para aqueles que propõem uma atuação e presença forte do poder público na promoção da educação como direito, este quadro pode parecer, não sem razão, bastante nega- 
tivo, senão desolador, considerando o intento de se construir uma sociedade, onde a expansão do acesso à educação se combine com sua qualidade.

A pergunta que aqui se coloca é: como entender esta situação da educação superior no Brasil de predomínio e fortalecimento do setor privado, em franco processo de oligopolização, justamente num período de governo em que as forças sociais se ampliam após longo inverno do governo militar, seguido de um período dúbio de inspiração neoliberal?

\section{ALGUMAS PISTAS PARA DECIFRAR O ENIGMA}

Para abrir pistas na busca de respostas a esta pergunta, é conveniente estabelecer um parâmetro de referência. Este parâmetrorefere-se às distinções ente educação e mercado.

O mercado é regido por valores e regras de funcionamento onde se combinam diminuição de custos e aumento de rentabilidade e lucro. A busca da elevação dos lucros enquanto valor supremo do mercado na sociedade capitalista, que com eles traz também o aumento de poder inclusive na esfera pública, está no cerne do seu jogo e define suas regras. Questões como função social da empresa, sustentabilidade, responsabilidade social, pertinência, que povoam os debates contemporâneos forçosamente ocupam lugar secundário, a não ser que se compatibilizem de alguma forma com a preservação dos lucros. Estas questões levam a uma discussão longa e profunda o que está longe da intenção deste artigo. Cabe apenas sinalizar aqui que estes são alguns aspectos fundamentais que levam a contrapor a ideia de educação superior com a ideia de mercado.

Quanto à educação superior, conforme assinala Bernheim (2010, p. 1023), a universidade, instituição surgida na Idade Média europeia, assumiu desde o seu nascimento o formato de "grêmio ou corporação dos que ensinam e aprendem, dos mestres e discípulos dedicados ao ofício de aprender os saberes”. Em meados do século XX, Polanyi (2003, p. 29) afirmava que a Universidade prima pela ciência, cuja essência "está no amor ao conhecimento e que a utilidade desse último não é nossa preocupação primordial". No caminhar dos seus nove séculos, prossegue Bernheim, sua existência vem se sustentando "no princípio da liberdade acadêmica", no primado da "investigação científica e a formação humana" (p. 1037-1038) incluindo aí a formação profissional.

Quando se fala, pois, em mercado e educação superior, sobretudo no seu formato de universidade, está-se referindo a fenômenos antitéticos: trata-se de instituições que, no âmbito da sociedade maior, operam distintamente. Os valores que sustentam sua existência e as regras que definem seu modo de 
operar estão em campos diferentes, senão opostos. Não está em questão aqui um julgamento que demoniza o mercado e exalta a universidade. Olhando para o mercado, seu desenvolvimento nos começos da modernidade europeia fez ressurgir a escravidão, traço da antiguidade que se julgava definitivamente sepultado. Persistiu nas Américas por quase quatro longos séculos, vindo a desaparecer somente na segunda metade do século XIX. O escritor Machado de Assis (1997, p. 31), observador dos costumes sociais no Brasil em fins do Império e início da República, tendo presenciado os extertores da escravidão no país, afirmava ser impossível "apagar a instituição da história". Olhando para a universidade, as armas nucleares, químicas e biológicas, cuja capacidade de destruição ultrapassa os limites da imaginação, são frutos das pesquisas em ciências básicas que brotaram do interior dos laboratórios de pesquisa das grandes universidades. Contudo, a mesma história nos obriga a um outro olhar: no despertar da modernidade ocidental, o desenvolvimento do mercado interligou povos e culturas distantes e diferentes, estimulou o desenvolvimento das cidades, ensejou a "Renascença" nas artes e nas ciências. Estas, cultivadas no interior das sociedades científicas e posteriormente incorporadas à Universidade, operaram enorme transformação da face mesma do planeta e das sociedades humanas que o habitam, estando hoje fortemente associadas ao desenvolvimento dos povos. Assim, o poder criador, tanto quanto o poder destruidor pode estar presente em ambas instituições - mercado e universidade. São fatos opostos, acontecimentos relacionados a instituições distintas, em tempos opostos a indicar sobre tudo a necessidade do controle democrático que assegure o cumprimento das funções sociais que justificam a existência de tais instituições.

Quando se fala em educação superior, importa destacar sua natureza como bem público e como direito humano, o que traz para o primeiro plano a importância das instituições que a promovem e da universidade no mundo contemporâneo. Ao mesmo tempo, os fatos aqui apresentados constituem uma grave advertência, indicando que a educação superior não pode operar pela lógica do mercado; no limite e no tempo será sua destruição enquanto instituição educativa, construtora de cidadania, na busca da verdade, parceira na criação de sociedades verdadeiramente democráticas. Isto requer o "fincar pé em princípios que não podem ser negociados" de sorte que a educação superior, muito além da especialização profissional passe a existir como "uma missão de estratégias para a vida” (DIAS SOBRINHO, 2005, p. 225-235).

A percepção destes fatos é fundamental para que uma sociedade escolha os caminhos que a levem à criação de formas de vida democráticas, construindo um sistema educacional que corrobore esta busca. Esta percepção é também 
fundamental para que seus agentes políticos sejam capazes, no âmbito do Estado, de forjar as condições para que isto ocorra.

Tomando estes parâmetros como referência, o argumento que aqui trazemos é o de que para entender o quadro da educação superior no Brasil no seu processo de privatização e oligopolização, é preciso ir além das posições que envolvem neoliberalismo e a influência de órgãos internacionais. Não se deve ignorar a importância dos debates com estes enfoques; negá-los certamente implicaria em prejuízo da compreensão do que ocorre no pais, num contexto de globalização. Contudo, para compreender os rumos da educação superior no país, é fundamental um olhar que incorpore o processo de formação das instituições políticas brasileiras, o exercício do poder, as práticas que elas ensejaram e que persistem até o presente, como que a desafiar o tempo.

Ao concluir seu livro, Faoro (2001, p. 819), cuja análise alcança a metade do século passado, alude ao fato de que decorridos cinco séculos de história do Brasil, "uma estrutura político-social resistiu a todas as transformações fundamentais, aos desafios mais profundos, à travessia do oceano largo". Nesta estrutura, já lembrava antes Holanda (2006, p. 144), "na esfera dos negócios [...] o freguês ou cliente há de assumir a posição de amigo"; os negócios privados se entrelaçam com os negócios públicos, como atesta fartamente a história do país; os partidos políticos se esvaziam no seu conteúdo e ação. Lamounier (2006, p. 292), no seu artigo "Sergio Buarque e os grilhões do passado", reafirma a atualidade da tese deste clássico da literatura política e histórica do Brasil, ao dizer "que, entre nós, o Estado democrático republicano só se afirmaria quando se "desprendesse" efetivamente dos particularismos sociais e do precedente estado patrimonialista, e a eles se contrapusesse como uma esfera pública impessoal".

Ao iniciar o século XXI, Lazzarini (2011a, p. 1-3; 109-120), em seu estudo sobre o "Capitalismo de laços: os donos do Brasil e suas conexões" afirma nas conclusões perceber mudanças nesta estrutura. Contudo, no decorrer do livro, sua argumentação reitera a predominância destas redes de contatos pessoais que criam canais de influência do setor privado para o setor público, do setor público para o setor privado, onde público e privado se entrelaçam e se confundem. Na introdução do livro, Lazzarini apresenta um fato significativo: a notícia de que o Brasil seria a sede dos Jogos Olímpicos de 2016 e o quanto este acontecimento foi influenciado pelo mega empresário Eike Batista responsável pelo aporte financeiro para sustentar o empreendimento; o mesmo Eike, maior doador da campanha presidencial que reelegeu Lula, tanto quanto o maior patrocinador do filme sobre a vida do ex-presidente. 
O autor não demoniza esta estrutura de relações pessoais, chegando mesmo a apontar aspectos positivos onde alianças entre o setor privado nacional e o poder público resultaram em ganhos econômicos para o país. De qualquer modo, este quadro tende a reiterar afirmação de Faoro, citada por Lazzarini, de que "assim é porque sempre foi" (2011a, p. 819). Nesta linha tênue entre o público e o privado, a atuação do poder público evidencia seus reflexos. Fato recente envolveu o Banco Nacional de Desenvolvimento Econômico e Social (BNDES), como financiador de uma mega fusão entre o grupo de supermercados brasileiro Pão de Açúcar e o grupo francês Carrefour,envolvendo uma soma astronômica de dinheiro público $(4,5$ bilhões de reais do BNDES, correspondendo a quase $90 \%$ do total de recursos envolvidos na operação) para viabilizar uma fusão de grupos privados, da qual surgiria o terceiro maior grupo varejista de alimentos no mundo, o maior do Brasil, e a segunda maior empresa brasileira depois da Vale do Rio Doce, com o poder de controle de mais de 1/3 do setor varejista no país; operação que só não foi concretizada devido a discordâncias entre os envolvidos no processo e à reação pública contrária, expressa sobretudo através da mídia.Este assunto foi por analisado artigos de De Chiara e Rehder (2011) e Lazzarini (2011b) no Jornal o Estado de São Paulo (Economia).

No que se refere à educação superior, a zona cinzenta entre o público e o privado apresenta consequências bastante significativas. No ano de 2002, passagem para um novo governo, os dados registravam uma forte ociosidade de vagas nas instituições privadas. Rezende Pinto (2004, p. 5-7) já constatava neste ano a "grande explosão do setor privado", indicando que entre 1995 e 2002, a oferta de vagas neste setor mais que dobrara; porém a relação candidato/vaga, forte indicador de demanda, neste ano foi de 1.6, enquanto nas públicas esta relação foi de 8.9. Em 2002, 37.4\% (553.084) das vagas no setor privado não foram preenchidas. Em suma, em termos econômicos, muita oferta e pouca procura. Esta situação configurava para o autor "o impasse a que chegou o modelo de expansão da educação superior via privatização". Com base em dados de 2004 , Martins $(2009$, p. 5) constata que " $49 \%$ das vagas do setor privado estavam sem ocupação" combinando este fato com "um aumento significativo do número de inadimplentes", o que para o autor apresentava "claros sinais de exaustão" da "política de expansão através da via privada".

Esse impasse de certa forma foi resolvido pelo Programa Universidade para Todos (PROUNI) instituído por Medida Provisória (n. 213) pelo Governo Federal em 2004. Foram e continuam sendo muitas as dúvidas sobre o acerto do PROUNI enquanto política pública visando ampliar o acesso das camadas da população de nível socioeconômico mais baixo a níveis superiores de 
educação, contributo, pois, à democratização da sociedade brasileira. Antes mesmo da aprovação e implementação do PROUNI, Davies (2004, p. 248-251) alertava, segundo seu ponto de vista, para "a diminuição da responsabilidade federal com a educação, em particular com a educação superior, e o incentivo à participação do setor privado". Em particular, o autor aponta o "verniz democratizante" presente na "ideia de renúncia fiscalpelo governo em troca de vagas ociosas em instituições privadas". Em artigo de 2004 (p. 6), Leher afirmava que, segundo estudo da Associação Nacional dos Dirigentes das Instituições Federais de Ensino Superior (ANDIFES) “com apenas R 1 bilhão seria possível generalizar o ensino noturno das IFES, criando aproximadamente 400 mil novas vagas. Com o total de verbas públicas que está sendo previsto para as instituições privadas seria viável criar mais de um milhão de novas vagas." Em artigo de 2006 (p. 8), Carvalho prossegue na mesma direção crítica, ao constatar que "não permitir o acréscimo de isenção fiscal às IES privadas possibilitaria um maior bolo de recursos constitucionalmente garantidos ao ensino público", "reduzindo o financiamento indireto via renúncia fiscal em troca de acréscimo no financiamento ao segmento federal". Agregando a este contexto o fato de que as matrículas nas IES públicas concentram-se no período diurno, ao contrário das particulares cuja matrícula se concentra no noturno, bem como ainda a existência de infraestrutura de laboratórios e salas de aulas nas instituições públicas, tudo isto sugere que os investimentos nas IES públicas seriam o caminho mais adequado a uma proposta de expansão da educação superior com qualidade e de caráter verdadeiramente democrático, que atenderia aquela população trabalhadora cuja maior chance de estudo está no período noturno.

Na contramão do que estas diversas análises sugerem a política de renúncia fiscal na educação superior privada cria um enorme volume de recursos financeiros e uma estabilidade de mercado garantido por lei, bem como elimina ou diminui grandemente os riscos dos investimentos; enfim, o melhor dos mundos para se ganhar dinheiro. O processo de oligopolização da educação superior e os ganhos de capital atrás mencionados, resultantes das operações nas bolsas podem ser assim melhor compreendidos: mercado privado fortalecido por recursos públicos. Ninguém vai à bolsa senão com a perspectiva de lucro; quanto maior a certeza deste, maior a valorização das ações. Portanto, situação ideal para os modernos capitalistas da educação que nas suas relações com o Estado, ou relações com o poder do momento percebem as oportunidades e buscam criar laços, subvertendo assim tanto as regras do mercado capitalista como as do Estado republicano enquanto promotor e assegurador do bem público. 
Dados de 2010 dão conta de que a quantidade de vagas ociosas nas instituições privadas diminuiu, voltando ao patamar de 2002, superior a $30 \%$. As vagas ociosas diminuíram, as matrículas na educação superior aumentaram. Contudo, esta constatação nãorepresentou avanços no equacionamento do problema da democratização da educação superior; ao contrário, pode tê-lo agravado, pois o Programa pode trazer um benefício apenas "simbólico àqueles que conseguirem permanecer no sistema e, talvez uma chance real de ascensão social para poucos que estudaram no seleto grupo de instituições privadas de qualidade. Mas para a maioria, cuja porta de entrada encontra-se em estabelecimentos lucrativos e com pouca tradição no setor educacional, o programa pode ser apenas uma ilusão e/ou uma promessa não cumprida." (CARVALHO, 2006, p. 8). Esta afirmação traz à tona a questão da expansão com qualidade. Conforme afirma Chaves (2010, p. 6), dados referentes a formados em Direito, em São Paulo e Campinas, por faculdades ligadas a um dos grandes grupos educacionais privados do país, indicam que a proporção de aprovados nos exames da Ordem dos Advogados do Brasil (OAB), não chega a 10\%. Operando segundo regras do mercado - diminuição de custos, grande parte das instituições particulares de educação superior, mencionando ainda Chaves, "não atende às exigências de um terço do corpo docente com titulação de mestres doutores em regime integral de trabalho, definidas na LDB". Embora muitas outras pesquisas desta natureza devam ser desenvolvidas junto a formados em outros cursos, já tendo ingressado no mercado de trabalho, é inegável que tal constatação representa um alerta quanto à qualidade da educação superior no país. Sinais que apontam para o amarelo, senão já para o vermelho, de uma situação a que se chegou pela preponderância do setor privado na expansão da educação superior, ironicamente com o suporte do poder público.

A análise aqui empreendida, espera-se, ajuda a compreender a conexão entre a olipolização/mercadorização da educação superior no Brasil e as relações de poder. Como visto, a zona cinzenta que embaça a distinção entre o público e o privado aparece com vigor nas políticas, nem tanto públicas, de educação superior, como de resto em políticas abrangendo outras esferas de atuação do Estado. A predominância do setor privado nesta importante área da vida brasileira e o processo de oligopolização que dela toma conta progressivamente podem ser melhor compreendidos se, juntamente com as forças globalizantes que impulsionam o capital se combinam as práticas políticas no país que desde um passado longínquo, pela força mesma deste passado, ou pelas conveniências de preservação do poder hoje, confundem o público e o privado. É como que uma força maior que atravessa a história do país desde suas origens, passa 
pelo período colonial, estende-se pelo império, chega até a república, subsiste na versão populista dos anos getulistas e seguintes, alcança o período militar e adentra os governos que o sucederam com fortes cores neoliberais, até chegar a um populismo ressurreto na primeira década do século XXI.

Em suma, o processo de privatização da educação superior no Brasil e o seu desdobramento na oligopolização recente, mais do que a ausência do Estado, indica, ao contrário presença deste, que se movimenta no interior de uma cultura política onde os limites entre o público e o privado são obscuros. Esta predominância da iniciativa privada na educação superior e consequente olipolização não reflete a ação da "mão invisível" das forças "criativas" do mercado, como queria Adam Smith; antes, revela a mão bastante visível do Estado, dela emergindo um "quase mercado", como assinala Dias Sobrinho (2002), mas na direção oposta estimulado pelo Estado, onde o risco é substituído pela quase certeza, fruto de grande volume de recursos financeiros gerados à custa de isenções fiscais; um mercado a atrair e concentrar investimentos privados num setor que deveria ser público por excelência. Nesta conjunção, as políticas públicas tendem a operar alianças e favorecer setores (dentro da esfera pública ou na esfera de poderosos grupos particulares) que ampliam o arco de sustentabilidade do poder vigente; arco que abarca movimentos sociais, sindicatos, movimento estudantil, empresários e partidos políticos, num vasto abraço de cooptação que busca eliminar possíveis oposições e garantir a manutenção do poder. É um jogo que a educação superior de qualidade no Brasil não está ganhando.

\section{REFERÊNCIAS}

ASSIS, Machado. Memorial de Aires. São Paulo: Globo, 1997. Obras completas de Machado de Assis.

BERNHEIM, Carlos Tünnermann. Desarrollo histórico de la Universidad. Cincuentenario de la Revista Paraguaya de Sociologia, Asunción, jun. 2010. Serie Educación

BRASIL. Ministério da Educação (MEC). Instituto Nacional de Estudos e Pesquisas Educacionais Anisio Teixeira. Censo da Educação Superior 2010. Brasília, outubro 2011. 
CARVALHO, Cristina Helena Almeida de. O PROUNI no governo Lula e o jogo político em torno do acesso ao ensino superior. Educ. Soc., Campinas, v. 27 , n. 96 , out. 2006.

CHAVES, Vera Lúcia Jacob. Expansão da privatização/mercantilização do ensino superior Brasileiro: a formação dos oligopólios. Educ. Soc., Campinas, v. 31, n. 111, abr./jun. 2010.

CUNHA, Luiz Antonio. A universidade crítica: o ensino superior na república populista. 3a ed. São Paulo: Editora UNESP, 2007.

DAVIES. Nicholas. O governo Lula e a educação: a deserção do Estado continua? Educ. Soc., Campinas, v. 25, n. 86, p. 245-252, abr. 2004.

DE CHIARA, Márcia; REHDER, Marcelo. Negócio polêmico: fusão no varejo depende do BNDES. O Estado de São Paulo, 29 jun. 2011. Economia, B1.

DIAS SOBRINHO, José. Universidade e Avaliação. Entre a ética e o mercado. Florianópolis: Insular, 2002.

. Dilemas da educação superior no mundo globalizado: sociedade do conhecimento ou economia do conhecimento? São Paulo: Casa do Psicólogo. 2005.

FAORO. Raymundo. Os donos do poder: formação do patronato político brasileiro. 3. ed. ver. São Paulo: Globo, 2001.

HOLANDA, Sergio Buarque de. Raízes do Brasil. ARAÚJO, Ricardo Benzaquen de, SCHWARCZ, Lilia Moritz (Orgs.). Ed. rev. São Paulo: Cia das Letras, 2006.

LAMOUNIER, Bolívar. Sérgio Buarque os "grilhões do passado". In: HOLANDA, Sérgio Buarque de. Raízes do Brasil. Edição comemorativa 70 anos. São Paulo: Cia das Letras, 2006.

LAZZARINI, Sérgio Giovanetti. Capitalismo de laços: os donos do poder e suas conexões. Rio de Janeiro: Elsevier, 2011a.

. Mais uma vez, política industrial sem critério. O Estado de São

Paulo, 29 jun. 2011b. Economia, B 3. 
LEHER, Roberto. Para silenciar os campi. Educ. Soc., Campinas, v. 25, n. 88 especial, out. 2004.

LORDELO, Carlos. Só 41\% dos formandos de cursos de saúde da Unip em SP fazem Enade. O Estado de São Paulo, 04 mar. 2012. Vida/Ambiente/ Ciência/Educação/Saúde/Sociedade, A22.

MARTINS, Carlos Benedito. A reforma universitária de 1968 e a abertura para o ensino superior privado no Brasil. Educ. Soc., Campinas, v. 30, n. 106, jan./abr. 2009.

OLIVEIRA, Romualdo Portela. A transformação da educação em mercadoria no Brasil. Educ. Soc., Campinas, v. 30, n. 108, out. 2009.

OSCAR, Naiana. As compras de empresas não vão parar (especial sobre educação da revista EXAME). EXAME, São Paulo, 25 jun. 2012.

OSMAN, Ricardo. O modelo de gestão de um setor que fatura muito, lucra bastante e tem ações na bolsa, mas não gosta de ser chamado de negócio. Istoé Dinheiro, São Paulo. 30 jul. 2008. Disponível em: <www. istoedinheiro.com.br/noticias/3855_LICOES+DA+EDUCACAO $>$. Acesso em: 17 jul. 2012.

POLANYI, Michael. A lógica da liberdade: reflexões e réplicas. Rio de Janeiro: Topbooks, 2003.

POMPEU, Sergio; LORDELO, Carlos; SILVA, Cedê. Unip é acusada de selecionar alunos para fazer Enade; MEC pede explicação. O Estado de São Paulo, São Paulo, 03 mar. /2012. Vida/Ciência/Educação/Saúde/Sociedade. A 22 .

REZENDE PINTO, José Marcelino de. O acesso à educação superior no Brasil. Educ. Soc., Campinas, v. 25, n. 88 especial, out. 2004.

SALDANHA, Paulo. Mais 30 universidade são suspeitas de terem "inflado" as notas do Enade. O Estado de São Paulo, São Paulo, 23 mar. 2012. Vida/ Ambiente/Ciência/Educação/Saúde/Sociedade, A 16. 
